\title{
Hypothesis
}

\section{A New Approach to the Treatment of Alzheimer's Disease: the Need for a Controlled Study}

\author{
Harry S. Goldsmith* \\ Clinical Professor of Neurological Surgery, University of California, Davis, CA, USA
}

Accepted 7 February 2011

\begin{abstract}
It has been widely believed that decreased cerebral blood flow (CBF), known to occur in Alzheimer's disease (AD), is the result of neuronal degeneration that causes a decrease in the need for adequate CBF. There is new interest in the idea, however, that it is not neuronal degeneration that leads to decreased CBF to critical neurons, but it is the decrease in CBF which is the cause of the neuronal deterioration seen in AD patients. In order to increase $\mathrm{CBF}$ to the AD brain, an operation called omental transposition has been developed in which an intact elongated omental pedicle, when placed directly on the brain, provides additional CBF and other biological nutrients to the brain. It is understandable that AD patients are awaiting a method to control their disease, but this may take years to become available. Placing the omentum on the AD brain has demonstrated increased CBF which may be the reason that several studies have shown that omental transposition to the brain can improve the cognitive ability of AD patients who have undergone the operation. What is needed is a prospective controlled study that could scientifically establish the benefit of the procedure.
\end{abstract}

Keywords: Alzheimer's disease, amyloid plaque, cerebral blood flow, omental transposition, omentum

A report in the June 10, 2010 issue of the New England Journal of Medicine (NEJM) carefully covered the clinical problems, strategies, and evidence related to Alzheimer's disease (AD) [1]. The subject is of extreme importance since 1,000 new cases of AD are reported daily throughout the United States [2]. The cause of AD remains unknown, but what is accepted is that in the $\mathrm{AD}$ brain there are three neuronal states: normally functioning neurons, dead neurons, and neurons that are slowly deteriorating. If a method was available to support the integrity of the deteriorating neurons, one might expect that the ravages of AD could be temporarily stabilized or even improved.

${ }^{*}$ Correspondence to: Dr. Harry S. Goldsmith, P.O. Box 493, Glenbrook, NV 89413, USA. Tel.: +1 775749 5801; Fax: +1 775749 5861; E-mail: Hlgldsmith@aol.com.
There is a continuing belief among many researchers of a relationship between the presence of amyloid plaque burden within the brain and the development of $\mathrm{AD}$. The major component of these amyloid plaques is amyloid- $\beta$ protein $(\mathrm{A} \beta)$ which has led to the belief that it is this protein that is responsible for the development of $\mathrm{AD}$. Increasing evidence is accruing, however, that amyloid plaques are the marker but not the underlying cause of $\mathrm{AD}$ and that cerebrovascular insufficiency may be the basis for the development of the disease [3].

Also theorized is that cerebral cholinergic deficiency may play a key role in the cognitive loss seen in $\mathrm{AD}$ patients. This idea is the basis for the continuing widespread use of cholinesterase inhibitors in $\mathrm{AD}$ which are drugs that are believed to impede the enzyme cholinesterase from breaking down acetylcholine (ACh). ACh is the neurotransmitter that is 
believed to be deficient in producing cholinergic transmission within areas of the brain involved with cognition and memory. This concept concerning ACh deserves consideration.

Choline acetyltransferase (ChAT) is the enzyme which is instrumental in the synthesis of ACh and serves as the specific marker for cholinergic neurons. If a lower level of $\mathrm{ACh}$ might be the basis for $\mathrm{AD}$, one would expect concentrations of ChAT to be depressed in $\mathrm{AD}$ patients as compared to normal controls. Studies of patients with mild cognitive impairment (MCI) and moderate AD were found to have ChAT levels which were no different than levels found in non-demented aging patients. ChAT levels were found elevated in the frontal cortex and hippocampus in patients with early MCI but were found reduced only in patients at the end stage of AD [4].

In the NEJM paper [1], donepezil (Aricept) was the preferred drug to be administered to patients with late MCI and early $\mathrm{AD}$, with this drug being given $5 \mathrm{mg}$ at night and raised to $10 \mathrm{mg}$ if the drug was well tolerated. It was advised that the drug be continued and the patient closely followed clinically along with repeated neurophysiological assessment over a two year period [1]. In spite of this hopeful but limited advice, cholinergic inhibitors continue to be the common method for the treatment of AD patients. Many of these cholinesterase-inhibitor drugs, however, show only a marginal benefit over a six month period and only a minimal percentage point improvement in the Alzheimer's Disease Assessment Scale [5]. Along with these limited functional improvements were adverse side effects reported by many patients [6]. Such results give little hope to many patients and caretakers involved with AD. In fact, the New York Times on June 24, 2010, said "There is no treatment to stop or slow the progress of AD."

For many years it has been theorized that the decrease in cerebral blood flow (CBF), which is present in $\mathrm{AD}$, is the result of neuronal degeneration within the $\mathrm{AD}$ brain that decreases the continued need for CBF. One might look at this in a different way; namely, that $\mathrm{AD}$ is not the result of neurodegeneration which decreases the need for CBF, but conversely it is the decrease in $\mathrm{CBF}$ which directly causes neural degeneration. This concept has led to increasing interest in the idea that cerebral hypoperfusion could be the basis for AD.

There is an approximate $0.5 \%$ per year decrease in $\mathrm{CBF}$ and blood velocity as one ages, which is a normal aging phenomenon [7]. In addition, there are other risk factors associated with aging that further decrease CBF such as hypertension, diabetes, and coronary artery disease. This decrease in $\mathrm{CBF}$ leads to inadequate oxygenation, lowered glucose levels, and limitation of biological substances normally delivered to the brain, which are crucial for survival of key neurons that are involved in the development of AD. If specific neurons, such as those involved in learning and memory, are deprived of optimal blood flow and biological substances that are carried by the blood flow, a serious disruption occurs in the intracellular energy system within the neuron itself. This disruption directly affects the intraneural mitochondria and endoplasmic reticulum, which has a decreasing effect on the production of adenosine triphosphate (ATP) (the energy source of a neuron). A reduction of ATP caused by a decreased $\mathrm{CBF}$ produces a negative effect on intracellular protein metabolism resulting in the production and accumulation of intracellular-extracellular $\mathrm{A} \beta$ peptide $[3,8]$. If a mass of neurons located in specific and critical areas in the brain (such as the hippocampus) lose neuronal energy over an extended period, this situation may eventually result in dementia of the AD type. These series of events strongly suggest that amyloid plaque is not the cause of AD but is the marker of the disease.

As interest in amyloid plaques is slowly losing consideration as being the cause of $\mathrm{AD}$ [3], the possibility that the basis for the disease is decreased CBF is steadily increasing. Suggestive of this is a phase contrast MRI study which measured the total volume of $\mathrm{CBF}$ that flowed to the brain of AD patients through the internal carotid and basilar arteries. A significant decrease in the volume of blood flow through these arteries was noted in $\mathrm{AD}$ patients who exhibited a mean blood flow of $442 \mathrm{ml} /$ minute as compared to a mean blood flow of $551 \mathrm{ml} /$ minute in non-demented age-matched subjects $(p<0.001)$. Comparable studies in a younger age group of normal subjects (median age 29 years) by this phase contrast MRI study demonstrated an even higher mean blood flow of $742 \mathrm{ml} /$ minute $[9,10]$.

The above study clearly showed a marked CBF decrease to the brains of elderly and AD patients as compared to young individuals. The idea that decreased $\mathrm{CBF}$ can lead to neuronal death and eventual AD is not new. It was first raised by de la Torre in 1993 [11] and again in a more recent publication where it was stated that "chronic or transient suboptimal brain perfusion can well contribute to the metabolic perturbations that are responsible for the lesions characteristic of AD" [12].

An additional study suggested that decreased CBF was not the only cause of $\mathrm{AD}$, but the velocity of the 
decreased CBF could also be implicated in AD development [13]. This was based on the findings of several thousand demented and non-demented elderly patients who demonstrated that decreased $\mathrm{CBF}$ coupled with diminished CBF velocity both apparently had a negative effect on ischemic sensitive neurons located in critical areas of the brain such as the hippocampus. As the volume of blood and its velocity diminishes to the brain, one can visualize the widespread neuronal deterioration that could lead over time to the development of AD.

There are additional risk factors causing cerebral hypoperfusion which may have the potential to cause AD. Histochemical studies have shown that brain capillaries in AD patients lose their structural configuration and eventually become twisted and kinked [14]. This change in capillary structure markedly affects the microcirculatory flow pattern through these vessels. Normally, blood flow through capillaries is laminar, but when the capillary loses it shape and becomes irregular in shape, as seen in capillary vessels in $\mathrm{AD}$, the blood flow pattern through these blood vessels reverts from normal linear flow to abnormal disturbed flow. As this irregular blood flow movement passes through abnormally shaped capillaries, it becomes another factor that decreases CBF to critical neurons located within the brain.

Additional histological changes are present within the vessel wall of capillaries in an AD brain that lead to cerebral hypoperfusion. These include basement membrane thickening, endothelial cell compression, perycyte degeneration, and vessel luminal distortion [15]. These physical presentations cause compression of the endothelial cells that line the walls of the capillaries. This compression causes a compromise of nitric oxide production that normally occurs within these endothelial cells which is important since it is nitric oxide production and release that controls the vascular dilation that allows for an increase in CBF. When endothelial cells are adversely affected, the lumen of arterioles loses its ability to dilate and CBF becomes limited. The above factors make for a strong possibility that they may be instrumental in the development of AD pathology.

\section{TREATMENT MODALITY}

If there is the possibility that decreased $\mathrm{CBF}$ could be the cause of $\mathrm{AD}$, every effort should be made to discover techniques that might increase blood flow to the brain. Unfortunately, there is no known method at present to introduce large volumes of blood into the brain except for an operative procedure in which a pedicled vascularized omentum is placed directly upon the brain. The operation is known as omental transposition. This surgical procedure has been shown to add a large volume of blood to the human brain over an extended period of time [16]. This procedure, when performed on $\mathrm{AD}$ patients, resulted in the reversal of symptoms in 9 of 25 AD patients [17]. Additional studies involving omental transposition also resulted in reversal of $\mathrm{AD}$ symptoms [18, 19].

Omental transposition to the brain of AD patients has been well described, and basically involves surgically elongating an intact pedicled omentum, which is brought up through a subcutaneous tunnel on the chest wall and along the lateral neck up to the brain. A craniotomy is performed and, after opening the dura, the omentum is simply laid directly on the brain. It is not operatively difficult. The operation has resulted in the clinical improvement that is believed to be due to the introduction into the brain of increased blood flow [16], as well as neurotransmitters [20], nerve growth factors [21], and vascular endothelial growth factor (VEGF) (the most angiogenic substance in the human body) with its greatest concentration located in omental tissue [22]. Additional studies have shown the presence of large numbers of stem cells in the human omentum [23].

Omental transposition is not a cure for $\mathrm{AD}$, but it has been shown to lead to cognitive and functional improvement in patients with changes lasting up to 3 to 4 years. One can speculate that if patients could receive the operation in the late stages of MCI or early $\mathrm{AD}$, there is the expectation that a large number of these patients would show improvement that would last for a longer period than has previously been observed.

Omental transposition requires surgery, and there is no question that a pharmaceutical approach to $\mathrm{AD}$ would be highly preferable to any surgical procedure. Great amounts of time and money have been spent at many centers throughout the world in the search for such a pharmaceutical method to address the adverse cognitive and neurologic change associated with AD. The crucial question for AD patients and their caretakers, however, is how much time it may take for the pharmaceutical industry to develop such a drug. Waiting years to produce such a drug to treat the disease is obviously a painful experience for AD patients and their caregivers. Omental transposition has been proven clinically beneficial for such a treatment which raises the question as to whether the operation should be presented by doctors to their AD patients. 
A recent publication has stated that "Alzheimer disease is incurable" [24]. I do not believe this. Dead neurons obviously cannot be retrieved, but neurons that are in the process of deterioration might be stabilized leading to improved intracellular energy production and cognitive function. A rigidly controlled study involving omental transposition to evaluate its effect on $\mathrm{AD}$ patients seems critically important and more than justified. It would mean a great deal to an $\mathrm{AD}$ patient and his or her caretaker to learn that there is a form of treatment that had been carefully studied which has led to cognitive improvement.

The ability of a patient to face an overwhelming medical problem such as AD would be well addressed if the individual learned that there was a form of treatment for such a devastating disease. Omental transposition is a procedure that can now be offered to an $\mathrm{AD}$ patient with the idea that the procedure has the potential to prove beneficial. It is understandable that individuals rarely wish to have an operation, but until a pharmaceutical method becomes available to prevent or control $\mathrm{AD}$, omental transposition is a procedure that can have a positive effect on the disease. It is an operation that can be performed today.

\section{DISCLOSURE STATEMENT}

The author's disclosure is available online (http:// www.j-alz.com/disclosures/view.php?id=762).

\section{REFERENCES}

[1] Mayeux M (2010) Early Alzheimer's disease. N Engl Journal 362, 2194-2201.

[2] Hebert LE, Scherr PA, Bennett DR, Evans DA (2004) Alzheimer disease in the US population: prevalence estimates using the 2000 census. Arch Neurol 61, 802-803.

[3] de la Torre JC (2000) Cerebral hypoperfusion, capillary degeneration and development of Alzheimer disease. Alzheimer Dis Assoc Disord 14, 573-581.

[4] Dekosky ST, Ikonomovic MD (2002) Upregulation of choline aceytyl-transferase activity in hippocampus and frontal cortex of elderly subjects with mild cognitive impairment. Ann Neurol 51, 145-155.

[5] Hansen RA, Gartlehner G, Webb AP, Morgan LC, Moore CG, Jonas DE (2008) Efficacy and safety of donepezil for treatment of Alzheimer's disease: a systematic review and meta-analysis. Clin Interv Aging 3, 211-225.

[6] Jackson S, Ham RJ, Wilkinson D (2004) The safety and tolerability of donepezil in patients with Alzheimer's disease. Br J Clin Pharmacol 58, 1-8.

[7] Leenders KL, Perani D, Lammertsma AA, Heather JD, Buckingham P, Healy MJ, Gibbs JM, Wise RJ, Hatazawa J, Herold S, et al. (1990) Cerebral blood flow, blood volume and oxygen utilization: normal values and effect of age. Brain 113, 27-47.
[8] Steiber A, Mourelatos Z, Gonatos NK (1996) In Alzheimer's disease the golgi apparatus of a population of neurons without neurofibrillary tangles is fragmented and atrophic. Am J Pathol 148, 415-426.

[9] Spilt A, Bok FMA, Van der Geest RJ, Reiber JH, Kunz P, Kamper AM, Blauw GJ, van Buchem MA (2002) Reproducibility of total cerebral blood flow measurements using phase contrast magnetic resonance imaging. J Magn Reson Imaging 16, $1-5$.

[10] Spilt A, Weverling-Rijnburger AWE, Middelkoop HAM, van Der Flier WM, Gussekloo J, de Craen AJ, Bollen EL, Blauw GJ, van Buchem MA, Westendorp RG (2005) Late-onset dementia: structural brain damage and total cerebral blood flow. Radiology 236, 990-995.

[11] de la Torre JC, Mussivand T (1993) Can disturbed brain microcirculation cause Alzheimer disease? Neurol Res 15, 153-156.

[12] Roher AE, Kokjohn TA, John TA, Beach TG (2006) An association with great implication: vascular pathology and Alzheimer disease. Alzheimer Dis Assoc Disord 20, 73-74.

[13] Ruitenberg A, Heijer TD, Bakker SLM (2005) Cerebral hypoperfusion and clinical onset of dementia: the Rotterdam study. Ann Neurol 57, 789-794.

[14] Fisher VW, Siddigia A, Yusufaly Y (1990) Altered abnormalities in selected areas of brains with Alzheimer disease. Acta Neuropathol 79, 672-679.

[15] de la Torre JC (2000) Cerebral hypoperfusion, capillary degeneration and development of Alzheimer. Dis Assoc Disord 14, 573-581.

[16] Goldsmith HS, Bacciu M, Cossu M, Pau A, Rodriguez G, Rosadini G, Ruju P, Sehrbundt Viale E, Turtas S, Viale GL (1990) Regional cerebral blood flow after omental transposition to the ischemic brain in man: a five year follow-up study. Acta Neurochir 106, 145-152.

[17] Goldsmith HS (2007) Omental transposition in treatment of Alzheimer disease. J Am Coll Surg 205, 800-804.

[18] Shankle Wr, Mena I, Hara J, O'Heany T, Bjornsen L, Gade G, Leport P, Ali M, Rayhaun A, Kim J, Malkazian D, Raimo M, Reyes L, Fallon J, Kim R (2006) NeuroSPECT demonstrates increased cortical activity in Alzheimer's disease patients for at least two years after omental transposition neurosurgery. Alasbimn 31, AJ31-1.

[19] Shankle WR, Hara J, Bjornsen L, Gade GF, Leport PC, Ali MB, Kim J, Raimo M, Reyes L, Amen D, Rudy L, O'Heany $\mathrm{T}$ (2008) Omental transposition surgery for patients with Alzheimer's disease: a case series. Neurol Rev 30, 313-325.

[20] Goldsmith HS, Mcintosh T, Vesina R, Colton T (1987) Vasoactive neurochemicals identified in omentum. $\mathrm{Br} \mathrm{J} \mathrm{Neu-}$ rosurg 1, 359-364.

[21] Siek G, Marquis JK, Goldsmith HS (1990) Experimental studies of omentum-derived neurotrophic factors. In: The Omentum: Research and Clinical Applications, Goldsmith HS, ed., Springer-Verlag, New York, pp. 109-116.

[22] Zhang QX, Magovern CJ, Mack CA, Budenbender KT, Ko W, Rosengart TK (1997) Vascular endothelial growth factor is the major angiogenic factor in omentum mechanism of the omentum-mediated angiogenesis. J Surg Res 67, 147-154.

[23] Garcia-Gomez I, Goldsmith HS, Angulo J, Prados A, LópezHervás P, Cuevas B, Dujovny M, Cuevas P (2005) Angiogenic capacity of human omental stem cells. Neurol Res 27, 807811.

[24] de la Torre (2010) Alzheimer's disease is incurable but preventable. J Alzheimers Dis 20, 861-870. 